\title{
SISTEMAS INTERÉTNICOS, MIRADA ETNOGRÁFICA E INVESTIGACIÓN HISTÓRICA EN EL NORORIENTE DE VENEZUELA DURANTE LA ÉPOCA COLONIAL
}

\author{
Interethnic Systems, Ethnographic View and Historical Research \\ in the Northeastern Venezuela during the Colonial Times
}

\author{
Francisco Tiapa \\ francisco.tiapa@gmail.com \\ Universidad de Los Andes. Venezuela \\ Fecha de recepción: 20/09/2018 \\ Fecha de aceptación: 17/01/2019
}

RESUMEN: La región del Nororiente de Venezuela, durante la época colonial, estuvo caracterizada por el contraste entre diferentes grupos étnicos y culturales. La reconstrucción de estas divergencias ha requerido de la proyección de las bases teóricas del método etnográfico hacia ámbitos que implican no solo la alteridad en el tiempo, sino alteridad en el espacio. En este trabajo se ilustra cómo este método, más que ser una técnica de recolección de datos es en sí una mirada que permite la relativización de la cultura de referencia y la aproximación hacia visiones de mundo divergentes con el punto de vista del observador. En la primera parte, se argumenta la relevancia de la mirada etnográfica para la crítica a la cultura de referencia del analista y de su proyección hacia el estudio histórico de fronteras multiculturales. En la segunda parte, se ilustra la aplicación de esta perspectiva en las fronteras étnicas del Nororiente de Venezuela durante la época colonial. En esta sección, el énfasis se establece sobre su importancia como recurso de auto-crítica cultural, la configuración de la mirada desde la alteridad, la aprehensión de otras formas de irreflexividad cultural y el reconocimiento de las diversas formas de complejidad social. Finalmente, se abre la reflexión en torno a los límites analíticos derivados de la separación entre la mirada histórica y la antropológica, debido a sus potenciales sesgos etnocéntricos al abordar el estudio de las diferencias culturales en el tiempo.

Palabras clave: etnografía; historia; crítica cultural; fronteras coloniales.

ABSTRACT: During the colonial times, the Northeastern Venezuela region was featured by the contrast between different ethnic and cultural groups. The reconstruction of these contrasts has required the projection of the theoretical bases of the ethnographic method towards scopes which 
imply both othernesses in time and in space. This paper illustrates how this method, more than a technique of data collection, is itself a theoretical look that allows the relativization of the analyst's own culture and the approach towards world views that diverge with the observer's point of view. In the first section, the relevance of the ethnographic looks for critiquing the analyst's culture of reference, inside the historical study of the multicultural frontiers, is argued. In the second section, the application of this perspective on the Noreastern Venezuela's frontiers, during the colonial times, is illustrated. In this main section, the focus is on the importance of this look as a resource of cultural self-critique; the approach of other ways of cultural irreflexivities; and the recognition of different ways of social complexity. Finally, this papers opens the reflection around the analytic limits of the separation between History and Anthropology, doubt their potential ethnocentric biases in the study of the past's cultural differences.

Keywords: ethnography; history; cultural critique; colonial frontiers.

SUMARIO: 1. Método etnográfico y crítica cultural en la Antropología histórica de las fronteras del Oriente de Venezuela. 2. El potencial teórico del método etnográfico en el estudio de los Sistemas Interétnicos del Oriente de Venezuela. 2.1. La relativización de la cultura de referencia. 2.2. Las miradas desde la alteridad. 2.3. Aprehensión de la irreflexividad de otras culturas. 2.4. Reconocimiento de otras formas de la complejidad. 3. Etnografía, Historia e irreflexividad cultural. 4. Conclusiones. 5. Referencias bibliográficas.

El método etnográfico ha sido posiblemente uno de los principales aportes desde la Antropología hacia el conocimiento occidental de los últimos dos siglos. Al ir más allá de los grandes eventos, los espacios institucionales, las grandes jerarquías políticas o las metodologías cuantitativas, el método etnográfico ha marcado una discontinuidad que aún hoy presenta potencialidades no exploradas. El contraste de este método con otras aproximaciones muestra cómo los pequeños actos cotidianos, irreflexiva e inconscientemente reproducidos a lo largo de la vida diaria de una sociedad en particular, presentan un escenario tan complejo como el de las estructuras corporativas de las sociedades industrializadas (cf. Kuper, [1999] 2001, p. 29). Aún más, al mostrar la complejidad donde se piensa que existe simplicidad, el método etnográfico ha permitido cuestionar a las bases etnocéntricas del pensamiento moderno, plasmadas en los sustratos mismos de las teorías evolucionistas (Sapir, [1921] 1975, p. 144; Whorf [1956] (1971), p. 101). La etnografía, llevada a una teorización de mayor alcance, no solo ha sido la plataforma para la crítica hacia la cultura de referencia de la Antropología, sino hacia la dimensión colonialista de su propio método (Clifford, [1983] 1991; Fabian, 1983; Pandian, 1985). Es decir, desde la experiencia etnográfica, la Antropología ha destacado como una disciplina capaz de revisarse y cuestionarse a sí misma.

Ahora bien, dado que la configuración histórica de la etnografía tuvo como contexto a la propia cultura de referencia que esta ha criticado, también existen sesgos y remanentes vigentes en sus bases contemporáneas. A partir del reconocimiento de esta coexistencia entre auto-crítica cultural y continuidad histórica de los sesgos etnocéntricos, en este espacio se presenta una reflexión sobre estas potencialidades dentro del campo de la Antropología Histórica de las fronteras coloniales del Norte de Sudamérica. A lo largo del eje central de este trabajo, se argumentará la 
aplicabilidad del método etnográfico en la reconstrucción de los sistemas interétnicos del Oriente de Venezuela, con énfasis en su capacidad para la superación de los remanentes etnocéntricos de la historiografía tradicional y como ejemplo susceptible de ser trasladado hacia otras regiones fronterizas del orden global. En la última parte, se esbozarán los contrastes entre la mirada etnográfica y las bases lógicas de las perspectivas historiográficas tradicionales. Asimismo, se abrirá la discusión en torno a las limitaciones del método etnográfico, una vez que este es proyectado hacia la reconstrucción de las dinámicas históricas de regiones definidas por las tensiones y contradicciones entre diferentes grupos étnicos y culturales. El referente geográfico es la transición entre la costa Norte del río Orinoco y la costa Sur-oriental del Mar Caribe durante la época colonial (Mapa n. 1 1), con énfasis en los siglos XVII y XVIII, momento en que la acción política de las misiones permitió un relativo control sobre las poblaciones indígenas de esta región (Gómez Canedo, 1967; Carrocera, 1968; Gómez Parente, 1979; González Oropeza, 1985).

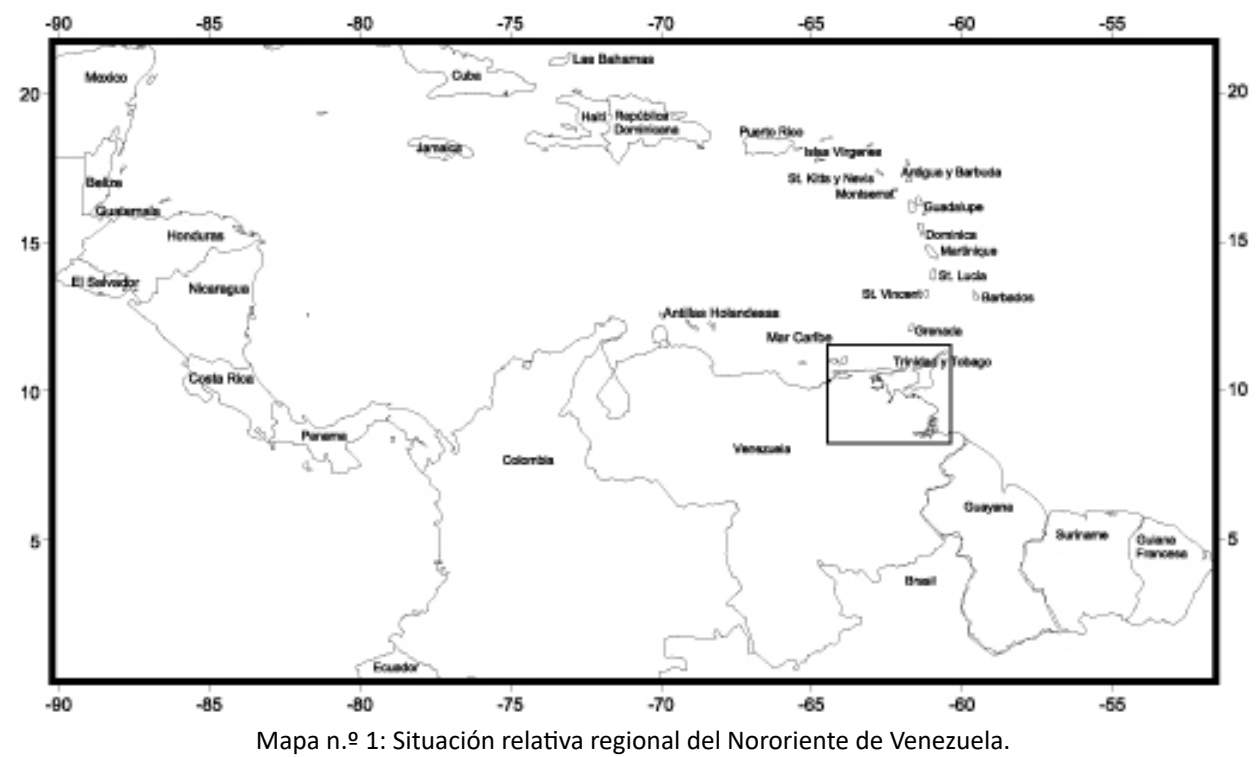

\section{MÉTODO ETNOGRÁFICO Y CRÍTICA CULTURAL EN LA ANTROPOLOGÍA HISTÓRICA DE LAS FRONTERAS DEL ORIENTE DE VENEZUELA}

El método etnográfico se sustenta sobre la idea de que la complejidad de una cultura cualquiera se expresa por medio de eventos cotidianos y microscópicos, reproducidos sin una explicación consciente por parte de los actores sociales. Tal ausencia de intencionalidad sería captada por medio de una convivencia de larga 
data, de al menos un ciclo de un año, en un sitio específico y circunscrito, donde el analista se insertaría en las rutinas cotidianas del grupo en cuestión. En una primera instancia, esta síntesis pareciera mostrar un método sencillo, donde el analista se limitaría a insertarse en otras vidas, para luego hacer un recuento anecdótico sobre ellas. Ahora bien, una interpretación así solo reafirmaría la idea de que mientras otras sociedades viven su existencia de manera irreflexiva, solo aquellas personas insertas en espacios institucionalizados serían capaces de elaborar ideas susceptibles de una proyección supra-cultural. En este segmento se mostrará cómo, una vez potenciada su dimensión axiomática, el método etnográfico es capaz de elaborar críticas culturales capaces de incidir sobre otras esferas disciplinarias. Para esto, se presentará una serie de vectores de caracterización de los sesgos eurocéntricos en la historia colonial del río Orinoco y del Oriente de Venezuela y cómo la aplicación de las bases teóricas del método etnográfico son capaces de trascender estos sesgos y dirigirse hacia la configuración de una historia sobre y desde las fronteras de la condición colonial.

La agenda de investigación en torno a los sistemas interétnicos del río Orinoco ha sido abordada desde el punto de vista arqueológico (Boomert, 2000; Gassón, 1996, 2000, 2002, 2003; Scaramelli y Tarble, 2005), histórico (Morey y Morey, 1975; Arvelo Jiménez, Morales y Biord, 1989; Zucchi y Gassón, 2002; Morales Méndez, 1990; Biord 1985; 2006; Biord y Arvelo, 2007; Dreyfus, 1983-1984; Amodio, 1991; 1998) y etnográfico (Thomas, 1972; Coppens, 1971; Butt-Colson, 1973; 1983-1984; Mansutti 1986; Zent, 2009). En tal sentido, su discusión ha sido transversal a la mayoría de las investigaciones abocadas a la comprensión histórica de las sociedades indígenas de esta región. Además de su transversalidad, esta línea de indagación tiene una serie de singularidades que hacen que, independientemente de su enfoque, sea necesaria una aplicación de las bases conceptuales del método etnográfico, pero con una mirada crítica que permita mostrar cuáles pueden llegar a ser sus limitaciones a fin de maximizar sus potencialidades. El trabajo en torno a los sistemas interétnicos es de escala regional; se enfoca en una región cultural y étnicamente diversa; muestra condiciones de constante cambio temporal y espacial; y se enfoca sobre un tipo de realidad sobre la cual no hay un referente inmediato de aprehensión empírica.

En el abordaje a los sistemas interétnicos, la escala de análisis implica un constante diálogo entre la mirada local y la mirada regional. En el primer caso, a partir de los referentes etnográficos actuales, ha sido posible inferir el mundo vivencial de las poblaciones indígenas que respondieron ante la avanzada colonial. Además, las investigaciones realizadas en la segunda mitad del siglo Xx mostraron de qué manera las poblaciones indígenas contemporáneas perciben su relación con otros pueblos indígenas y con la sociedad nacional venezolana (Thomas, 1973; Butt-Colson, 1973; 1983-1984). En el segundo caso, es posible abordar a la condición colonial en articulación con las dinámicas geopolíticas indígenas como variable de contraste con 
las dinámicas enfocadas sobre espacios circunscritos. De este modo, se ha trascendido la idea de que las sociedades indígenas de las tierras bajas sudamericanas son culturas aisladas, de pequeña escala y organizativamente simples, para abrir el abanico hacia una perspectiva más amplia sobre sus capacidades de articulación más allá de los límites locales. En otras palabras, esta línea de investigación ha abierto el umbral hacia la teorización sobre otras formas de configuración geopolítica, más allá de la idea generalizada y ubicua de que solo las sociedades industriales son capaces de organizarse sobre los niveles más básicos de la integración social.

La condición de diversidad étnica y cultural de los sistemas interétnicos ha sido singularmente patente en la región de transición entre la cuenca del Orinoco y la costa Sur-Oriental del Caribe. Durante la época colonial, el Oriente de Venezuela estuvo poblado por los pueblos indígenas Cumanagoto, Chacopata, Píritu, Tagare, Core, Kuaka, Chaima, Paria y Kari'ña, de filiación lingüística Caribe; sumado a grupos de otras familias lingüísticas, como los Arawaks y los Warao. Asimismo, la presencia europea no se limitó al caso de los españoles, sino que hubo asentamientos franceses en el Golfo de Paria (Pelleprat, [1655] 1985, p. 48, pp. 50-51, pp. 84-85, 90), enclaves holandeses en las salinas del río Unare (Civrieux, 1980, p. 89; Caulín, [1779] 1968, II, pp. 29-30; AGI, Santo Domingo, 641, [06-12-1647] 1967, , p. 66; AGI, Santo Domingo, 641, 31-10-1656; AGI, Santo Domingo, 641, 24-09-1659), así como presencia de navegantes ingleses en Paria y en el Morichal largo, uno de los ríos del Delta del Orinoco (AGI, Caracas, 164, [1763] 1985, p. 150). No menos importante fue la presencia de grupos criollos no europeos, como las poblaciones afrodescendientes y las así llamadas "castas» del orden colonial, como los pardos, mulatos y zambos (Ríonegro, 1921, pp. 176-177; AGI, Santo Domingo, 639, [02-12-1700] 1967, pp. 143-144; AGI, Santo Domingo, 642, [11-01-1713] 1968, p. 349; AGI, Santo Domingo, 644, [31-05-1752] 1968, pp. 180-181). Esto ha llevado a que el abordaje metodológico haga una diferencia con las aproximaciones clásicas enfocadas sobre una realidad culturalmente homogénea cuya tendencia hacia el contraste se centra en la dicotomía criollo/indígena o europeo/indígena. Tal multiplicidad estuvo presente tanto en los espacios de las poblaciones indígenas como en el caso de los diferentes grupos no indígenas, como fueron las áreas circundantes a pueblos como Cumanacoa, Cariaco, Carúpano, Río Caribe y Güiria (AGI, Santo Domingo, 576; AGI, Santo Domingo, 632; AGI, Santo Domingo, 606: 01-01-1736; AGI, Santo Domingo, 705, [03-06-1735], 1968; AGI, Santo Domingo, 624, [16-04-1745]1968; Ríonegro 1928).

Los pueblos indígenas que habitaron la región establecieron contrastes que no necesariamente fueron correspondientes con la homologación entre etnia y tendencia política. Por ejemplo, en el transcurso del siglo XVII los Cumanagoto estuvieron en contraposición con la presencia de los españoles (AGI, Santo Domingo, 641, [1656] 1967, I, p. 87), pero hacia principios del siglo XVIII estuvieron a favor de estos y en contra de los Kari'ña. Tales contrastes también se presentaron en el ámbito 
intra-étnico; por ejemplo, los Paria estuvieron conectados por redes de parentesco (AGI, Santo Domingo, 642: 16-08-1712), pero divididos entre sí por medio de conflictos entre caciques de la costa Norte y de la costa Sur de la Península (AGI, Santo Domingo, 189). Lo mismo ocurrió con los Chaima y con los Palenques, quienes en diferentes momentos mostraron fisiones internas y diferentes formas de conexión con grupos antagónicos con los españoles, como el caso de los Kari'ña (AGI, Santo Domingo, 641).

Por su parte, la heterogeneidad presente en las esferas de grupos criollos no «blancos» no solo lleva a romper con la oposición europeo/indígena, sino que es susceptible de ser trasladada al presente para cuestionar la oposición indígena/ criollo. De esta manera, se amplía la perspectiva hacia diferentes formas de diversidad donde las organizaciones indígenas tuvieron la capacidad de reacomodo y, aún más, de asimilación de otras identidades dentro de su plataforma organizativa.

El cambio constante en la investigación sobre los sistemas interétnicos del Oriente de Venezuela también ha llevado a trascender la oposición entre acontecimiento y estructura (Gaboriau, 1969, pp. 94-99; Sahlins, 1997, pp. 9-13), hacia el reconocimiento de la condición de cambio constante de las alianzas y redes de integración regional indígena. En la época colonial, tales cambios fueron tanto la derivación de las acciones impulsadas por los agentes coloniales como por los propios agentes indígenas (Whitehead, 1988; 1992; 1993; 1994). En tal sentido, más que ser Una Historia donde la presencia colonial muestra una condición activa en contraste con la recepción pasiva de las poblaciones indígenas, el cambio estuvo relacionado con la condición mutuamente constitutiva de las voliciones coloniales e indígenas, en medio de sus propios constreñimientos estructurales.

Esta condición de cambio estuvo definida por la lógica de transformación vigente en cada región, a su vez fluctuante según sus constituciones étnicas. No fue la misma dinámica de cambio entre los Chaima de las tierras altas de Caripe, quienes no manejaban la navegación en el Delta del Orinoco, que entre los Chaima de la costa de Paria, quienes no solo navegaban por los caños, sino que eran fluidos hablantes del Warao (AGN, Indígenas, Tomo 4). A estas condiciones intrínsecas se asociaban las relaciones con la dinámica más amplia definida por la avanzada del sistema colonial y las respuestas de los propios liderazgos indígenas hacia el avance misional y militar de los españoles.

El cambio constante fue constitutivo de la red de interconexión entre regiones, pues las historicidades regionales y locales no representaron unidades aisladas, sino que estuvieron en contaste complementariedad, contradicción y competición entre sí. Tales relaciones no se restringieron únicamente a la conexión con la sociedad colonial, sino a las conexiones entre diferentes regiones indígenas. Esto incluía no solo a aquellas que se relacionaban por medio de la acción de los líderes coloniales, sino a las regiones conectadas entre sí, más allá de la capacidad perceptiva de los europeos. 
Finalmente, la investigación en torno a la historia de los sistemas interétnicos del Oriente de Venezuela se caracteriza por ser una realidad a la que solo es posible acceder desde los testimonios de la cultura colonial, pero paradójicamente muestra un tipo de complejidad que esta mirada no es capaz de concebir. Esta característica presenta dos retos, por un lado, la superación de los sesgos en los testimonios y, por el otro, la fugacidad de las integraciones regionales indígenas. En el primer caso, los testimonios parten de una visión que en sí misma niega irreflexivamente la complejidad sociopolítica indígena. Tal negación se encuentra imbricada con el sustrato colonial de la negación de la capacidad generadora de cultura de estos pueblos. En el segundo caso, los propios agentes indígenas intencionalmente buscaron esconder su capacidad organizativa, especialmente cuando estas organizaciones tenían capacidades subversivas. Esto estuvo particularmente presente en la región del Nororiente de Venezuela, donde los sistemas se reconfiguraron dentro de los perímetros controlados por el orden colonial, como las Encomiendas, misiones y pueblos de doctrina. En estos espacios, la sobrevivencia de las organizaciones indígenas dependió de que estas pudiesen pasar desapercibidas para las autoridades coloniales. En tal sentido, esta agenda de investigación, en concreto la llevada a cabo en la región del Nororiente de Venezuela, requiere la reconstrucción de formas de organización a partir de fragmentos que pasan por diferentes niveles de decantación. Frente a estas fragmentaciones, la aplicación de las bases teóricas del método etnográfico es tan necesaria que la crítica de sus limitaciones se vuelve aún más urgente. En la siguiente sección se abordará la capacidad de traslado teórico del método etnográfico, con énfasis en sus aportes a la singularidad del enfoque de la Antropología Histórica frente a otras corrientes de investigación historiográfica.

\section{EL POTENCIAL TEÓRICO DEL MÉTODO ETNOGRÁFICO EN EL ESTUDIO DE LOS SISTEMAS INTERÉTNICOS DEL ORIENTE DE VENEZUELA}

Más que una metodología de recopilación de datos, el método etnográfico es en sí una propuesta teórica. Aún más, como forma de aproximación a la visión de mundo de otras culturas, se distancia de otros medios de representación de la realidad social, como los métodos estadísticos o la búsqueda de estructuras formales (Comaroff y Comaroff, 1992, p. 8, p. 20, p. 22). En la agenda de trabajo en torno a los sistemas interétnicos del Nor-Oriente de la cuenca del Orinoco, desde el punto de vista de la Antropología Histórica, la singularidad de las bases teóricas del método etnográfico lleva a que esta mirada no solo potencie su status epistemológico frente a otros enfoques disciplinarios, sino que le otorgue una mayor relevancia a aquellas historicidades configuradas desde patrones culturales contrastantes con los referentes perceptivos del analista. Aún más, este método muestra la potencialidad epistemológica de las historias fronterizas frente a las historias basadas 
en realidades que se imaginan como culturalmente homogéneas. En este espacio se proponen cuatro vectores de caracterización teórica, basados en los principios básicos que sostienen la misma disciplina antropológica. En primer lugar, se encuentra la relativización de la cultura de referencia del analista; segundo, la configuración de una mirada desde la alteridad; tercero, la búsqueda de la irreflexividad de otras culturas; y cuarto, el reconocimiento de la complejidad donde la mirada etnocéntrica solo ve simplicidad.

\subsection{La relativización de la cultura de referencia}

La mirada desde afuera de la cultura de referencia de aquella persona que realiza el trabajo etnográfico es la base misma de los horizontes teóricos de la Antropología (Marcus y Fisher, 1986, p. 1, pp. 4-6). Efectivamente, esta búsqueda de desensamblaje de los propios ámbitos irreflexivos del antropólogo ha estado acompañada de la búsqueda de formulaciones axiomáticas con tendencia a la universalidad (Balandier, 1993, pp. 35-36). Sin embargo, estos axiomas se han orientado a la propia sociedad del observador a partir del reconocimiento de la alteridad en aquellos con quienes se convive cotidianamente en los momentos que formalmente no se hace "etnografía» (cf. Augé, 1996). Desde el abordaje a los sistemas interétnicos del Orinoco, es posible sugerir que esta relativización se sustenta en la des-universalización del punto de vista de quien construye conocimiento antropológico, el cuestionamiento de la existencia de principios éticos universales, el reconocimiento de la variabilidad local de las visiones de mundo, la búsqueda de la mirada del otro como plataforma de análisis y la elaboración de marcos teóricos dirigidos al acceso hacia realidades inaprehensibles por medio de la observación directa.

Para la mirada antropológica el punto de vista de quien enuncia no es el referente de lo ideal, al menos para las diversas y hasta antagónicas corrientes críticas a los sesgos etnocéntricos del evolucionismo (Rosaldo [1986] 2000, p. 16; Marcus y Fisher, 1986, p. 10; Comaroff y Comaroff, 1992, p. 4), pues la cultura de referencia de quien observa y analiza no se concibe como la forma más pura o acabada de una sociedad. Por contraste con otras corrientes de pensamiento que elaboran una retórica de la Historia según un metarrelato -en el sentido de Lyotard, (1987)- idealizado sobre lo que se piensa que es La Humanidad, la mirada antropológica parte del principio de que la cultura de referencia es una entre otras. A esto se suma que, en las otras culturas, no se puede buscar el reflejo de los modelos idealizados que el analista tiene sobre su propio modo de vida. A partir de este principio de auto-cuestionamiento, en los sistemas interétnicos del Oriente es posible abrir el abanico perceptivo hacia otras tendencias de cambio que una mirada intracultural consideraría involución. Tal es el caso de las fugas de las misiones (AGI, Santo Domingo, 641, 08-11-1663; AGI, Santo Domingo, 641, 26-03-1690; AGI, Santo Domingo, 642, 20-03-1704; AGI, Santo Domingo, 643, 15-04-1730; AGN, Indígenas, t. 4, f. 
270v-271), el aislamiento consciente de los Warao del Delta (AGN, Indígenas, t. 4) y la configuración de culturas criollas alternas al orden colonial en la península de Paria a finales del siglo XVIII (AGN, Indígenas, t. 4, f. 224v-225; AGI, Caracas, 202). A esto se suman tendencias de cambio contradictorias, como las negociaciones de los líderes indígenas con los agentes representativos de la condición colonial (AGI, Santo Domingo, 641, 24-09-1659; AGI, Santo Domingo, 590, 29-12-1734; AGI, Santo Domingo, 632, 23-03-1735) o las apropiaciones de elementos culturales del origen europeo, a fin de mantener ámbitos de continuidad histórica de las autonomías políticas indígenas, como fue el caso de los Kari'ña (Whitehead, 1988; Morales Méndez, 1991; Amodio, 1998).

El cuestionamiento de los principios éticos universales deriva de que una de las principales premisas del método etnográfico reside en que toda cultura construye sus propios principios morales y que la mirada antropológica no puede juzgar a otra realidad a partir de sus propios preceptos de distinción entre lo que considera correcto o incorrecto. Tal tolerancia hacia otras formas de representar los linderos entre el bien y el mal, se adhieren al fundamento ético de la propia antropología, según el cual su producción de conocimiento está dirigida hacia la reafirmación y reivindicación de la diversidad cultural a lo largo del globo (cf. Garzón Valdés, 1997, p. 32). En tal sentido, la única prescripción estaría en sistemas culturales que en sí mismos son supresores de la diversidad cultural, como el colonialismo o el fascismo, bien sea que estos se presenten en el pasado o que se manifiesten en el presente. Al abordar fenómenos como la esclavitud o el canibalismo entre los Kari'ña (Whitethead, 1988, pp. 175-179) o la asimilación de afrodescendientes esclavizados entre los Paria (AGI, Santo Domingo, 189) no se busca en las otras culturas la representación del pasado prístino pre-cultural que la filosofía roussoniana busca proyectar. Tal imagen tiende a infantilizar a la diferencia, a partir del esquema racista de su encapsulamiento en un punto intermedio entre la animalidad y la humanidad (Chukwudi-Eze, 2001, pp. 243-244). Aún más, al elaborar una imagen idealizada de la diferencia se prescribe como debe ser esa diferencia; es decir, se impone autoritariamente una condición de existencia preestablecida que, de no cumplirse, se puede llegar a perder el derecho a ser reconocida.

La búsqueda de la variabilidad local de las visiones de mundo tiene sus bases en la misma antropología relativista (Sapir, [1921] 1975; Whorf [1956] 1971; Rosaldo, [1986] 2000). Entre otros ámbitos de indagación, en los sistemas interétnicos del Orinoco, esta forma de relativización ha permitido abrir la mirada hacia el reconocimiento de la diversidad de formas de concebir el sentido del centro y la periferia. En las reconstrucciones históricas basadas en esquemas intraculturales (Ojer, 1966; Carrocera, 1968; Lucena Giraldo, 1992) la empresa colonial se muestra como un recorrido teleológico hacia los máximos logros de la civilización. Por el contrario, a partir de la conexión entre praxis y visión de mundo, que es un lugar común de la mirada antropológica, es posible visibilizar cómo la serranía de Caripe, entre el 
siglo XVII y XVIII, fue un centro geopolítico debido a que era el centro de los liderazgos shamánicos de la región (AGI, Santo Domingo, 632, 08-03-1736; 02-05-1736). Este también es el caso de las reuniones en sitios rituales clandestinos dentro del perímetro de las misiones, que para los autores de los documentos no eran más que «bebezones» donde los indígenas iban a matarse entre sí (AGN, Indígenas, $t$. 4, f. 255-256v). En estos casos ha sido posible sugerir que el sentido del centro y la periferia no coincide con aquello que las historiografías etnocéntricas buscan mostrar, pues así como el sentido de la temporalidad es relativa también lo es el de la espacialidad (cf. Coronil, 2002).

El foco sobre el punto de vista del nativo (Malinowski, [1922] 1973, p. 41), como axioma de la investigación etnográfica, ha permitido la identificación de las articulaciones indígenas más allá de la mirada colonial. Tal es el caso de la identificación de la articulación supra-local indígena por medio de las fugas o desplazamientos voluntarios entre las poblaciones bajo el control de los españoles (AGI, Caracas, 184, [21-12-1757], 1968, pp. 224-225; AGI, Santo Domingo, 642, 16-081712) o las retiradas a los conucos por parte de los Kari'ña (AGN, Sec. Traslados. Col. Cumaná, t. 4. Doc. 4, folios 75-128) como forma de cohesión identitaria. A pesar de haber sido formulado por la Antropología Funcionalista, este principio ha marcado un contraste con otros proyectos universalistas del pensamiento occidental. Tal contraste puede establecerse incluso con las corrientes de pensamiento que, aunque buscan cuestionar al pensamiento moderno, lo hacen a partir de una historia monocultural y centrada en un referente histórico homogéneo (cf. Taylor, 1989). Claramente, la crítica a la cultura de referencia es en sí un punto que debe ser reconocido; sin embargo, si esta crítica se hace a partir de la invisibilización de otras formas de representación cultural, difícilmente se puede trascender el esquema de la simplicidad anclada a la tradición característica del pensamiento colonial.

Finalmente, la relativización necesariamente parte de la elaboración de modelos teóricos que permitan ver desde fuera tanto el mundo del analista como desde dentro a otro mundos (Lévi-Strauss, [1958] 1969, p. 303). A pesar de que las críticas contemporáneas al universalismo muestran esta tendencia como una forma de abstracción del colonialismo (cf. Dussel, 2000), es posible sugerir que la posibilidad de configuración de una mirada que observe desde fuera a la propia cultura abre el umbral para el des-centramiento de las historias eurocéntricas y el cuestionamiento de los proyectos nacionalistas contemporáneos (Nederveen-Pieterse, 1996, p. 2529). El uso de modelos teóricos para la relativización se basa en el método comparativo y en la unificación de fragmentos por medio de una aprensión de datos donde no hay generalizaciones previas acerca de sus condiciones sustantivas. En primer lugar la relativización a partir de la elaboración de modelos teóricos permite la comparación entre diferentes realidades culturales a fin de identificar patrones de continuidad o discontinuidad (Lévi-Strauss, [1958] 1969, p. 301-308; Balandier, 1993, 
p. 36). Por ejemplo, la comparación entre diferentes tipos de respuesta al colonialismo, como entre las fronteras del Orinoco en la época colonial con realidades como el Putumayo de principios del siglo xx (Taussig, 2002, p. 42-57), permite elaborar un marco más amplio sobre el terror como condición intrínseca de la condición colonial. Tal comparación es asimismo extensible a los Hohotï del Bajo Ventuari, quienes establecen su identidad a partir de la imagen del aislamiento consciente como respuesta a la violencia ejercida por los criollos durante la época de explotación del caucho. En segundo lugar, el modelo teórico permite la unificación de ámbitos de la realidad que, ante una primera mirada, se presentan de forma fragmentaria. Así, en las misiones de Oriente, gracias a la plataforma teórica que conecta a espacio con identidad, las fugas no son actos marginales ni las misiones son lugares de obstrucción de los intercambios. Por el contrario, estos son vistos como parte de los centros de integración regional (Tiapa, 2013), pues fueron espacios de intersección entre las redes comerciales indígenas, criollas y europeas; por lo tanto, su centralidad en los sistemas regionales no puede pasar desapercibida. Al ser abordados desde la premisa de que los espacios de encuentro entre diferentes universos culturales son también ámbitos de constante significación, eéstos también pueden ser concebidos como espacios de creatividad y de generación de nuevos universos de sentido (cf. Sahlins, 1997, p. 10) proyectados en la geopolítica de sistemas regionales. En tercer lugar, los fragmentos son unificados a partir de la conexión directa entre el analista y los testimonios involuntariamente plasmados en los documentos, a su vez sustentados sobre micro-acontecimientos cotidianos (Ginzburg, 1983, p. 62). Esta premisa contrasta con los trabajos basados en otras generalizaciones, como las crónicas o los testimonios de viajeros, pues se parte del principio de que incluso cuando se hace descripción, se está haciendo interpretación y esta forma de representación debe estar teóricamente sustentada a fin de superar la opacidad de la propia cultura y de aquella que se busca comprender (Geertz, 1996, p. 27). En el caso de la Antropología Histórica de los sistemas interétnicos, esta disipación al mismo tiempo que la unificación, se basa más en la conexión entre mirada y vivencia como principio epistemológico central. Para el trabajo histórico, la imposibilidad de la vivencia se sustituye con el ensamblaje de acontecimientos que tendrían una aparente relación entre sí, pero que, una vez unificados, pueden a llegar a mostrar estructuras de una escala más amplia que las circunscripciones de los micro acontecimientos narrados en la evidencia documental.

\subsection{Las miradas desde la alteridad}

Tanto en el abordaje de sociedades contemporáneas, como en las sociedades del pasado, la mirada etnográfica se basa en el principio de la alteridad. Aún más, en las bases de las corrientes del relativismo cultural y del estructuralismo, la historia se considera homologable con la etnografía porque ambas se basan en la mirada 
de la alteridad. Sea una distancia en el tiempo o una distancia en el pasado, estas miradas tienen en común que buscan observar a sus ámbitos de indagación desde fuera (Geertz, 1992, p. 58). Esta mirada de la alteridad se proyecta hacia los ámbitos naturalizados de la propia visión de mundo, al mismo tiempo que se busca el posicionamiento desde la mirada del otro.

En el caso de la historia de los sistemas interétnicos, la condición multicultural de su composición lleva a que uno de los principales ámbitos culturales a desnaturalizar sea el de las representaciones del tiempo. A partir de la idea de que cada conjunto culturalmente heterogéneo se construye a partir del solapamiento entre diferentes concepciones del tiempo, se elabora el principio de que la lógica temporal del analista no es la misma que aquella configurada dentro de los sistemas interétnicos. Las múltiples lógicas temporales se expresaron en contradicciones como la continuidad cultural de la Península de Paria, que fue la primera en ser contactada a finales del siglo $\mathrm{XV}$, pero la última en ser colonizada, a mediados del siglo XVIII (Aguado, [1581] 1950; Ojer, 1966; Carrocera, 1968). En tal sentido, esta necesidad de una mirada desde la alteridad hacia el tiempo del analista reside en el reconocimiento de la continuidad entre sus propias lógicas de tiempo y las lógicas de tiempo de la cultura colonizadora (Tiapa, 2008; Fabian, 1983, p. 25). En el abordaje de los sistemas interétnicos del Oriente en particular y de la cuenca del Orinoco en general, esta relativización del tiempo se ubica en los espacios fronterizos y esos no son solo fronteras en el sentido en que los entiende el analista, sino también dentro de los márgenes de espacios que no serían considerados fronterizos desde el punto de vista colonizador.

La aprehensión de la mirada del otro tiene como plataforma el reconocimiento del sesgo cultural de la óptica etnográfica y del hecho de que esta se encuentra construida a partir de principios teóricos preliminares. En este sentido, la historia de los sistemas interétnicos busca reconstruir conjuntos de organizaciones sociopolíticas con características ajenas a las visiones de mundo de los autores de los testimonios. De hecho, aún hoy, para el caso de las tierras bajas sudamericanas estas organizaciones no son completamente familiares a la mirada de la Antropología (cf. Duin, 2009). Por lo tanto, para acceder a estas formas de organización, dado que la mirada del otro es fragmentaria y sesgada, la mirada teórica, cuando busca observar a la cultura de referencia desde fuera, es en sí una forma de elaboración de artificios eruditos sobre las otras perspectivas de la realidad (Geertz, 1996; Comaroff y Comaroff, 1992; Rosaldo [1989] 2000).

\subsection{Aprehensión de la irreflexividad de otras culturas}

Mientras que la mayoría de las corrientes metodológicas de las Ciencias Sociales buscan sustentos empíricos basados en acciones conscientes, la etnografía se sustenta sobre los actos irreflexivos y dispersos a lo largo de la existencia cotidiana 
de las sociedades en estudio. Esta tendencia en el método etnográfico contrasta con metodologías como las entrevistas en el campo de la Sociología o el énfasis sobre los grandes acontecimientos en la corriente historicista. En primer lugar, en el traslado de las bases teóricas del método hacia la historia de los sistemas interétnicos, se parte de la idea de que el punto de vista del nativo no se expresa conscientemente, ni se sintetiza en un compendio separado de la existencia, sino en fragmentos diluidos en la vida diaria (cf. Comaroff y Comaroff, 1992, p. 34). En segundo lugar, se encuentra el enunciado malinowskiano de que el foco de nuestra atención debe orientarse hacia los imponderables de la vida real (Malinowski, [1922] 1973, p. 36), por medio de la preparación para los eventos inesperados. Este principio teórico se manifiesta en el trabajo de las historias fronterizas a través de la búsqueda de praxis cotidianas más allá de los grandes eventos (Geertz, 1996, p. 32) y con el reconocimiento de que la complejidad de las grandes escalas se expresan por medio de microcosmos exteriorizados en las pequeñas localidades (Lévi Strauss [1952] 1993; Geertz [1973] 1996; Sahlins [1985] 1997).

En tercer lugar, la complejidad intrínseca de los sistemas interétnicos es aprehensible por medio de acciones rutinarias y contingentes diluidas en la vida diaria de las sociedades en estudio. En tal sentido, el énfasis estaría sobre eventos fragmentarios que arbitrariamente representarían cosmovisiones más complejas por medio de respuestas accidentales a los cambios exógenos (cf. Rival, 2002). No solo para el caso de los órdenes cosmológicos, sino en otros niveles estructurales dentro de las cuales cada evento cotidiano representa pequeñas partes que tienen a una dimensión más amplia detrás de sí. En tal sentido, más que ser una estructura que se presenta ante la mirada del analista de forma coherentemente organizada, las organizaciones sociopolíticas indígenas dentro el orden colonial son sistemas que solo se exteriorizan contingentemente. Su manera de mostrarse ante la mirada histórica pareciera ser internamente incoherente y no como una forma acabada. Tal es el caso de los ejemplos de mito-praxis en las sociedades amazónicas, que muestran cómo las grandes narrativas subyacentes se exteriorizan solo por medio de la improvisación diluida en la vida diaria (Rival, 2002; Duin, 2009). En el abordaje de los sistemas interétnicos del Oriente, esta complejidad no evidente se expresó por medio de articulaciones supra-locales basadas en motivaciones que fueron más allá de las redes de intercambio, como ocurrió con las fisiones intraétnicas entre los Chaima del valle de Ropopán (AGN, Indígenas, t. 4, fols. 215-303). En estos casos, las conexiones regionales se mostraron de forma involuntaria, como actos fallidos. Metodológicamente, esto otorga una mayor centralidad a documentos históricos como los informes militares o misionales, frente a fuentes que tradicionalmente se perciben como privilegiadas, como los relatos de los cronistas. Tal preferencia se basa en que los primeros expresan micro-contingencias, mientras que los segundos muestran grandes generalizaciones. Así, la mirada etnográfica permite identificar complejidades donde una mirada intracultural se mantendría adherida a la idea de 
la ausencia de organización; es decir, la perspectiva etnográfica trasladada hacia otros ámbitos diferentes a la observación directa, permite acceder a niveles más allá de la invisibilización impuesta por la mirada colonizadora. La identificación de las estructuras políticas de escala regional, en este caso, se hace en contextos organizativos que siguiendo a Pagden ([1982]1988), fueron usados por los teóricos hispanos para argumentar en pro de la idea de la ausencia de organización en las sociedades no estatales como justificación para la asíllamada Guerra Justa (Pagden, [1982]1988, pp. 51-64).

Finalmente, como corolario de la relativización de los principios éticos del analista, la mirada etnográfica observa y participa, pero no busca intervenir. No se busca cambiar la cultura observada a partir de los propios esquemas idealizados. En el caso de las otredades en el tiempo, los principios idealizados de la Historia, míticamente determinados (Fabian, 1983, p. 7) necesariamente quedan fuera del espectro del análisis. En la historia indígena de Oriente -además del canibalismo o la esclavitud- los ataques de los indígenas rebeldes contra aquellos insertos en el rango de las misiones (AGN, Traslados-Cumaná, t. 80, f. 56; AGI, Santo Domingo, 189, Ramo 2, № 54, f. 2v: 01-1698; AGI, Santo Domingo, 632, 01-03-1725; Caulín II, [1779] 1966, pp. 191-192), podrían insertarse en una valoración ética negativa. Sin embargo, no solo estos tendrían que ser vistos en el marco de las tensiones y contradicciones de las relaciones coloniales, sino que, no pueden pasar ni siquiera por la búsqueda de una valoración positiva.

\subsection{Reconocimiento de otras formas de la complejidad}

En sí mismo, el método etnográfico es la aplicación práctica del principio teórico de que otras formas culturales no son menos complejas que la sociedad industrial solo por el hecho de no enfocar sus proyecciones de futuro sobre la elaboración de infraestructuras materiales. Por otro lado, el método se apoya en la idea de que no existe una conexión directa entre las dimensiones demográficas y la complejidad de una sociedad (en particular Lévi Strauss [1952] 1993). Las otras formas de complejidad pueden expresarse en escalas regionales como las organizaciones supra-étnicas en las rebeliones del siglo XVI (Arellano Moreno, 1964 Ojer, 1966; Jiménez, 1986), las cuales fueron imperceptibles ante la mirada de los autores de los testimonios históricos. De una manera diferente, esta complejidad también se exterioriza por medio de las organizaciones políticas dentro del rango del sistema de Encomiendas, también inexistente desde el punto de vista de quienes redactaron documentos históricos como la Visita del Oidor Riva Agüero, en 1689 (Prato-Perelli, 1990). Entre los Chaima del Valle de Ropopán, a finales del siglo XVIII, lo que parecía un conflicto entre dos facciones étnicas, provenientes de dos ríos diferentes y concentradas en la misión de San Félix Cantalicio, fue la expresión local de las fisiones entre diferentes sistemas interétnicos configurados en la época pre-misional. En 
esta fisión, el río Guarapiche había sido el epicentro de los grupos antagónicos con la presencia hispana, compuestos por los Chaima y los Kari'ña, junto con los fugitivos de las Encomiendas y de las misiones asentadas en la costa del Mar Caribe (AGI, Santo Domingo, 641, 26-04-1695; Pelleprat, [1655] 1965). En estas alianzas políticas, hubo grupos que o bien estuvieron insertos en el orden misional o bien establecieron sus solidaridades con segmentos alternos tanto al sistema colonial como a los liderazgos indígenas del Guarapiche. Por ejemplo, los Chaima de Caripe, aunque estuvieron en condición de contradicción con la imposición de las misiones hasta las primeras dos décadas del siglo XVIII (Caulín, [1779] 1966; Carrocera, 1968), hacia finales de este siglo tampoco mostraron tener cohesión con los Chaima de las tierras bajas cercanas a los caños del Delta del Orinoco, los cuales, a su vez, mantuvieron una tendencia a la contraposición a las políticas de adoctrinamiento cristiano (AGN, Indígenas, t. 4; AGI; Caracas, 169).

En definitiva, la mirada etnográfica va más allá de la idea de que solo se registra aquello que rompe con la rutina o aquello que se muestra como singular. Más allá de las posibles tendencias exotizantes que proyecta la Antropología fuera de sus límites disciplinarios (Comaroff y Comaroff, 1992), la etnografía busca registrar lo que pasa cuando se cree que no pasa nada. Dado que la cultura no se presenta como forma acabada, esta se busca en los eventos diluidos en la vida diaria. Por ejemplo, en visitas públicas como la de José Antonio Diguja en 1761 (AGN, Sección Traslados, Colección Cumaná, t. 52) o la de Luis de Chávez y Mendoza en 1783 (AGI, Caracas, 159-164), se muestra cómo los eventos microscópicos y cotidianos nos hablan sobre dinámicas de construcción de identidad, representaciones del espacio, relaciones alrededor de la vida material o de articulaciones supra-locales.

En suma, el método etnográfico es más que solo una forma de recolección de datos por medio de la observación directa. Este se orienta hacia la configuración de una perspectiva teórica similar a la del psicoanálisis, pero con atención primordial a las acciones involuntarias. Más que ser una polémica entre aquello que los integrantes de un grupo cualquiera dicen que hacen en relación con lo que hacen, se trata de indagar en esa contradicción, buscando el contraste entre el nivel retórico y el nivel conductual de un grupo. En el caso de los sistemas interétnicos del Orinoco, la mirada etnográfica, trasladada a la Historia, abre el abanico para fenómenos que, desde una mirada circunscrita a un referente culturalmente homogéneo, no tendrían más que una presencia fragmentaria y marginal. Tal capacidad de unificación deriva del vínculo estrecho entre perspectiva teórica, representación y aproximación empírica a la realidad. Aún más, los pequeños comportamientos, los actos rutinarios, los eventos de escala microscópica son, para esta mirada, expresión de complejidad, de singularidad y de cambio constante, incluso cuando se cree que no hay cambio. De este modo, la etnografía abre el umbral hacia costumbres y procesos que, de otra manera, serían imperceptibles. 


\section{ETNOGRAFÍA, HISTORIA E IRREFLEXIVIDAD CULTURAL}

La mirada etnográfica tiene la potencialidad de marcar una discontinuidad con las corrientes historiográficas ancladas en principios intra-culturales de representación del tiempo. Desde la experiencia de investigación dirigida a la reconstrucción de la dinámica de los sistemas interétnicos dentro del marco de las Encomiendas, misiones y doctrinas del Oriente de Venezuela es posible delinear preliminarmente cuáles son estos principios. En primer lugar, al estar basada en los esquemas del sentido común de su cultura de referencia, la mirada historiográfica clásica corre el riesgo de ser monocultural, pues tiende a universalizar esquemas de valoración de la Historia a partir de la idea de que su realidad de referencia es la única posible. En segundo lugar, esta mirada monocultural tiende a invisibilizar la relevancia de las diferencias étnicas dentro de las dinámicas históricas globales. Las historias sobre las fronteras coloniales inscritas en estos esquemas intraculturales (cf. Ojer, 1966; Carrocera, 1968; Lucena Giraldo, 1992) muestran como la categoría de «indio» no solo se usa acríticamente, sino que se inserta dentro de la narrativa histórica según las mitologías neocoloniales del Estado Nación. En tercer lugar, estas mitologías tienen como sustrato a la universalización del sentido unilineal del Tiempo, basada en los principios de la religión judeo-cristiana (cf. Le Goff, 1991; Fabian, 1983). En cuarto lugar- como ya se ha sugerido-, al igual que en otros espacios de las Ciencias Sociales (cf. Wallerstein, 1996), desde la lógica del tiempo unilineal, acumulativo y progresivo, se asocia diferencia cultural con simplicidad, según la idea fetichista de que la complejidad solo es concebible si esta se asocia con condiciones infraestructurales de una sociedad (cf. Pagden ([1982]1988); Coronil, 2002). Finalmente, la irreflexividad intracultural en las narrativas históricas neocoloniales deriva en el establecimiento de secuencias de causalidades que marcan un recorrido con el lugar de enunciación de quien marca el relato como el desenlace de un recorrido al cual se subordinan en las otras historias. Es decir, el presente del analista como destino del pasado.

Por otra parte, la exposición de las potencialidades del método etnográfico no puede convertirse en una retórica de construcción de identidad patrimonial dirigida a proyectar la sobreposición de la Antropología frente a otras miradas. Al ser una mirada basada en la auto-crítica y, aún más, en la crítica cultural, desde la perspectiva etnográfica también es posible hacer una aproximación hacia sus propias limitaciones. La necesidad de tal aproximación permite la maximización de las potencialidades expuestas, pues lleva a la puesta en evidencia de los lastres etnocéntricos de la etnografía, cuyos horizontes están precisamente en la superación de estos remanentes intraculturales. Por esta razón, el resaltado de sus capacidades axiomáticas no puede tornar en una retórica dirigida a la creación de una ilusión de superioridad o de universalidad.

Los límites del método etnográfico pueden identificarse en los mismos contextos retóricos en que se encuentra su capacidad para distinguirse de otros campos 
del saber con mayor integración intra-cultural. Más aún, en las bases lógicas de la etnografía, se encuentra un conjunto de principios que marcan su modelo idealizado de realización práctica en los preceptos que distinguen a un texto etnográfico clásico. A fin de abrir el abanico hacia discusiones futuras, preliminarmente se puede sugerir una serie de ejes de discusión en torno a las continuidades intraculturales de la mirada etnográfica. Tales continuidades derivan de los proyectos teóricopolíticos que contextualizaron su origen en el siglo XIX (Kuper, [1999] 2001, pp. 2629) cuya vigencia contemporánea reside en su imperceptibilidad. En primer lugar, al tener sus orígenes en un esquema cultural que se atribuye la exclusividad en la capacidad de cambio dinámico y constante, el método etnográfico se orienta hacia la búsqueda de esencias estructurales, susceptibles de ser homologables con modelos a-históricos sobre las sociedades contrastantes con el contexto de pertenencia del analista. En segundo lugar, al partir de la idea ubicua de la auto-contención y la simplicidad de las sociedades no industrializadas y al naturalizar la división entre cultura y poder, la mirada etnográfica tiende a marginalizar a las tensiones y contradicciones dentro de los ámbitos de indagación. No se trata de que las relaciones conflictivas no sean ilustradas, sino que la contradicción interna tiene un carácter periférico en relación con la imagen equilibrada de los sistemas culturales. En tercer lugar, como una derivación de los vectores anteriores, la inclinación a des-historizar a la diferencia lleva a que una contingencia espacial y temporal sea representativa de la universalidad de las sociedades en estudio. De este modo, para cada cultura, existirían ámbitos representativos de su autenticidad, por lo tanto, de su permanencia inamovible en el tiempo y de su expansión totalizante sobre el espacio.

Estas tendencias en la mirada etnográfica se mantienen como premisas no enunciadas que se imponen como los rigores abstractos en las investigaciones antropológicas clásicas. Como ejes reflexión, estos vectores parten de las singularidades de los ámbitos de indagación como los sistemas multiénticos del Oriente Venezuela, donde las condiciones de constante cambio, de contraposiciones políticas y de interconexiones más allá de lo local establecen un reto a los principios lógicos de la etnografía.

\section{CONCLUSIONES}

Las historias de las fronteras étnicas del río Orinoco y del Oriente de Venezuela muestran una especificidad frente a los esquemas tradicionalmente abordados por las Ciencias Sociales. La condición de constantes asimilaciones, fusiones, fisiones y etnogénesis de esta región contrastan con la idea de que una sociedad se encuentra integrada por una cultura internamente homogénea, dentro de unos límites territoriales claramente delineados. Tal imagen tiene una mayor correspondencia con las retóricas políticas de los Estados Nacionales Modernos que con la forma en que 
la misma historia europea configuró su entramado multicultural. Por otra parte, en las Encomiendas, misiones y doctrinas impuestas sobre las sociedades indígenas de esta región, las contradicciones y fricciones características del orden colonial tuvieron una mayor visibilidad que en contextos donde estas relaciones de dominación se presentan de forma opaca (cf. Geertz, 1996). En contextos como eéstos, las corrientes historiográficas eurocéntricas tenderían a presentar una historia unilineal, marcada por un solo pueblo dirigido al máximo estadio del progreso (Fabian, 1983, p. 143). Aunque dentro de estas corrientes puede llegar a reconocerse las contradicciones (cf. Casanova, 1991), estas serían contempladas dentro de un único marco cultural, negando la capacidad creativa y adaptativa de las sociedades ajenas al así llamado Occidente. Por contraste, las historias fronterizas muestran una multiplicidad que no puede ser marginalizada, pues en sí mismas las historias fronterizas son la historia del orden global (cf. Dussel, 2000).

El desarrollo de una agenda argumentativa que lleve a la superación de estos remanentes intraculturales es una tarea necesaria, pues el fin de la mirada etnográfica no es otra cosa que superar los esquemas etnocéntricos de invisibilización de la complejidad de las sociedades sujetas a los órdenes coloniales y neocoloniales. Tales esquemas muestran su vigencia en las corrientes historiográficas tradicionales, como principios naturalizados y diluidos en el sentido común de las narrativas del tiempo unilineal. La historiografía tradicional, al marginalizar la discusión hacia la crítica cultural, se presenta como un relato monocultural y eurocéntrico, que invisibiliza a las diferencias étnicas, que se sustenta en los esquemas unilineales del Tiempo y que se organiza en modelos abstractos de secuencias de causalidad. Tal patrón irreflexivo de la Historia es aún un reto por superar y, en ese sentido, la mirada etnográfica tiene aún mucho por decir. Ahora bien, esta mirada tiene la capacidad de crear una discontinuidad con las versiones históricas del racismo epistémico que enmarcan nuestros preceptos irreflexivos sobre la diferencia en el espacio y en el tiempo. A pesar de que esta comparte sus marcos perceptivos con el colonialismo, la mirada etnográfica se funda en el cuestionamiento de la misma plataforma cultural que sustenta su legitimidad. En este cuestionamiento se encuentra su dimensión epistémica, entendida en este espacio como su capacidad para generar fisuras conceptuales más allá de sus contextos de configuración no deliberada.

Desde las historias multiétnicas de las fronteras coloniales del río Orinoco, la caracterización de las potencialidades del método etnográfico se dirige hacia la maximización de sus capacidades para la elaboración de una crítica cultural (Marcus y Fisher, 1986, p. 4). Estas potencialidades no pueden percibirse como una autoalabanza monolítica e inamovible. Se trata de una apreciación preliminar que tiene como prioridad deslastrarse del colonialismo epistemológico; por lo tanto, no solo se encuentra sujeta a revisión, sino que el auto-cuestionamiento es un fin en sí mismo. Lo mismo aplica a la enumeración de los principios irreflexivos presentes en las versiones clásicas de la narrativa histórica y en la etnografía. No se trata de hacer un 
trazo grueso o una deslegitimación, sino de mostrar cómo los preceptos que marcaron a estos campos de conocimiento desde sus orígenes disciplinarios (cf. Wallerstein, 2006) se han filtrado como sentido común compartido de manera ubicua y opaca. De hecho, al estar asociados con las bases disciplinarias, estos principios, cuando no se muestran, pueden llegar a tener un efecto prescriptivo y supresivo hacia cualquier intento de innovación o de crítica. En suma, el status epistemológico de la etnografía pasa precisamente por lograr una mirada epistémica (cf. Foucault, [1969] 1979) como forma de exteriorización de la cultura del analista. En este caso, se trata de la cultura del eurocentrismo y del neocolonialismo como modelo retórico que rige al conocimiento institucionalizado. En tal sentido, aún queda mucho por decir sobre el valor deconstructivo de la etnografía, aún más desde las historias de los sistemas multiétnicos de las fronteras del orden global.

\section{Siglas utilizadas}

AGI: Archivo General de Indias, Sevilla.

AGN: Archivo General de la Nación, Caracas.

\section{Fuentes documentales inéditas}

AGI, Caracas, 159-164. Expedientes relativos a la Visita de Luis de Chávez y Mendoza a los pueblos de indios de la Provincia de Cumaná en 1783. Años de 1783 y 1784.

AGI; Caracas, 169: Testimonio de los autos relativos a la representación del Padre Fray Silvestre de Zaragoza hacha a S.M. sobre los Yndios del pueblos de Caripe en la Provincia de Cumaná. 12 de enero de 1788. 113 folios.

AGI, Santo Domingo, 189: Expediente de cartas e informes, dirigidos al gobernador de Cumaná y al Consejo de Indias, en los que se pide una entrada armada a las poblaciones indígenas de Paria. Se incluyen informes sobre entradas a los ríos Tigre y Guanipa, sobre negociaciones con los caciques de Paria, sobre las cimarroneras Chaima de Paria y sobre el comercio con los franceses de las Antillas Menores. Año de 1696. 24 folios.

AGI, Santo Domingo, 590: 29-12-1734: Certificación del Consejo de Indias ante El Rey, dando cuenta de las negociaciones del gobernador de Cumaná, Carlos Sucre, con los caciques del Golfo de Paria y del río Orinoco. 5 folios. 
AGI, Santo Domingo, 606: 01-01-1736: Carta de Carlos Sucre, gobernador de Cumaná, al Consejo de Indias, informando sobre la fundación de la misión de San Carlos Borromeo de Amacuro, en la península de Paria. 4 folios.

AGI, Santo Domingo, 632 02-05-1736: Carta de Fray Juan de Lóngares, prefecto de la misión de los Capuchinos aragoneses en Cumaná, al Consejo de Indias sobre las entradas armadas realizadas por el Marqués de San Felipe y Santiago contra los indígenas de la Serranía de Punceres y sobre la fundación de una nueva misión en el sitio de Caratal. 22 folios.

AGI, Santo Domingo, 632: 01-03-1725: Carta del sargento mayor, Cristobal Félix de Guzmán, al Rey, informando sobre sus acciones mientras fue gobernador del la isla de Trinidad, sobre las relaciones entre Caribes y holandeses y sobre el proyecto de fundar una ciudad de españoles en el río Guarapiche.

AGI, Santo Domingo, 632: 08-03-1736: Informe del Marqués de San Felipe y Santiago al Rey, sobre las entradas de reducción en el Golfo de Paria y la Serranía Punceres contra los indígenas que allí habitan. 4 folios.

AGI, Santo Domingo, 632: 23-03-1735: Carta del gobernador de Cumaná, Carlos Sucre, al Consejo de Indias informado sobre las negociaciones con los caciques del Orinoco. 6 folios.

AGI, Santo Domingo, 641: 08-11-1663: Real Cédula en la que se ordena el traslado de familias de españoles a las misiones de Píritu a fin de ayudar a los misioneros con la reducción de los indígenas de esa región. 1 folio.

AGI, Santo Domingo, 641: 24-09-1659: Real Cédula donde se emiten instrucciones sobre el poblamiento de la Provincia de Nueva Barcelona y sobre la asistencia a los misioneros para la reducción de los indígenas que la poblaban. 5 folios.

AGI, Santo Domingo, 641: 26-03-1690: Carta de Fray Antonio de Torrelacarcel al Consejo de Indias sobre la fundación de un pueblo de españoles y sobre las relaciones entre los Caribes y los franceses de las Antillas. 2 folios.

AGI, Santo Domingo, 641: 26-04-1695: Informe de Andrés Blanco al gobernador de Cumaná, sobre su entrada en búsqueda de ganado vacuno a los Llanos, la persecución de Caribes y su encuentro con los indígenas del río Tigre. Fechado el 26 de abril de 1695. AGI, Santo Domingo, 641. 2 folios y su vuelto. 
AGI, Santo Domingo, 641: 31-10-1656: Carta de Fray Lorenzo de Magallón, capuchino, al Consejo de Indias sobre el estado de la Provincia de Nueva Barcelona y sobre las relaciones de los indígenas Cumanagotos, Chacopatas, Píritus, Palenques con los holandeses y sobre la explotación de las salinas del río Unare. 2 folios.

AGI, Santo Domingo, 642: 16-08-1712: Informe de fray Pablo de Godojos al Consejo de Indias, en el que describe el traslado de los habitantes de la misión de Santa Isabel de Paria a la misión de San Francisco de Chacaracuar e incluye los padrones generales de ambos pueblos. 16 de agosto de 1712. 21 folios y su vuelto.

AGI, Santo Domingo, 642: 20-03-1704: Informe del Gobernador de Cumaná, José Ramírez de Arellano sobre la organización de entradas de reducción de los indígenas que habitaban en el perímetro de las misiones de Píritu. 10 folios.

AGI, Santo Domingo, 643: 15-04-1730: Carta del Obispo de Puerto Rico al Consejo de Indias sobre el estado de las misiones de los capuchinos aragoneses en Cumaná, sobre la falta de misioneros y sobre las largas distancias entre ellas. 4 folios.

AGN, Indígenas, Tomo 4. Expediente de cartas e informes de varios autores sobre la liberación de tributos a los habitantes del pueblo de Caripe, a fin de emplearlos como guías en las reducciones de los indígenas de los caños del Delta del Orinoco. Se describe la situación de las misiones de los Llanos orientales, la costa de Paria y las reducciones realizadas desde la provincia de Guayana. Años 1785-1798. Tomo 4, folios 222-305v.

AGN, Sec. Traslados. Col. Cumaná, Tomo 4. Doc. 4, folios 75-128: Visita del Oidor Luis de Chávez y Mendoza a las misiones de Parire, Cachipo, Cari, Tabaro, Múcuras y Quiamare. Año de 1783.

AGN, Sección Traslados, Colección Cumaná, Tomo 52. Informes y expedientes acerca de la visita del gobernador de Cumaná Don José Diguja Villagomez a los pueblos de indios de la provincia de Cumaná. Año de 1761.

AGN, Sección Traslados, Colección Cumaná, Tomo 80: Residencia al gobernador de Cumaná, Don Diego de Arroyo Daza, por Juan Ramos. Interrogatorios donde se trató la guerra a los Caribes y a esclavos rebeldes. 26 de agosto de 1626. 


\section{Fuentes documentales publicadas}

AGI, Caracas, 164: 1783. Expediente de la Visita del oidor, Luis de Chávez y Mendoza al pueblo de Curatequiche, en 1783. Burguera, Magaly (1985). Instituciones de comunidad: Provincia de Cumaná, 1700-1828 (Vol. 36). Academia Nacional de la Historia. Caracas, p. 150.

AGI, Caracas, 184: 21-12-1757. El Prefecto de la misión de Cumaná, P. Angel de Albalate, expone al Rey como no se había podido llevar a cabo la restauración temporal y espiritual de los pueblos de doctrina, devueltos a los Capuchinos en 1753, a causa de las contradicciones y oposiciones de los corregidores, y pide se cumplan, bajo severos castigos, las disposiciones dadas y que cita en su exposición. Santa María de los Ángeles, 21 de diciembre de 1757. En Carrocera, Buenaventura (1968): Misión de los Capuchinos en Cumaná. Tomo III. Caracas, Academia Nacional de la Historia, p.p. 217-232.

AGI, Santo Domingo, 576: 15-11-1730. Estado de las misiones de los Capuchinos en Cumaná y pueblos de doctrina por ellos fundados, dado por el obispo de Puerto Rico, D. Fr. Sebastián Pizarro, después de la visita pastoral, Cumaná, 15 de Noviembre de 1730. En Carrocera, Buenaventura (1968): Misión de los Capuchinos en Cumaná. Tomo II. Caracas, Academia Nacional de la Historia, p.p. 413-424.

AGI, Santo Domingo, 624, 16-04-1745. Relación de la visita del gobernador de Cumaná, D. Gregorio Espinoza de los Monteros, a los pueblos de doctrina, fundados por los Capuchinos en aquella provincia y ahora a cargo de clérigos seculares, y también a las misiones de los citados religiosos. 19 de febrero-16 de abril de 1745. En Carrocera, Buenaventura (1968): Misión de los Capuchinos en Cumaná. Tomo III. Caracas, Academia Nacional de la Historia, p.p. 124-154.

AGI, Santo Domingo, 639, 29-09-1701. Relación del P. Matías Ruíz Blanco sobre los antecedentes de la conquista de la Nueva Andalucía, estado y necesidades de las Misiones de Píritu, presentada a S.M. 29 de septiembre de 1701. En Gómez Canedo, Lino (1967): Las misiones de Píritu. Documentos para su historia. Tomo I. Caracas, Academia Nacional de la Historia, p.p. 110-125.

AGI, Santo Domingo, 639, 02-12-1700. Ordenanzas para los pueblos de las Misiones de la provincia del Píritu, que están a cargo de los religiosos franciscanos de la Observancia, 02 de diciembre de 1700. Gobernador José Ramírez de Arellano. En Gómez Canedo, Lino (1967): Las misiones de Píritu. 
Documentos para su historia. Tomo I. Caracas, Academia Nacional de la Historia, pp. 126-147.

AGI, Santo Domingo, 641: 06-12-1647. El obispo de Puerto Rico, Fray Damián López de Haro, remite al Rey (Margarita, 06 de diciembre de 1647) otro memorial del capitán Francisco Rodríguez Leite (Nueva Barcelona, 27 de junio de 1647) sobre la pacificación y evangelización de los indios de aquellas provincias. AGI, Santo Domingo, 623: 27 de junio de 1647. En Gómez Canedo, Lino (1967): Las misiones de Píritu. Documentos para su historia. Tomo I. Caracas, Academia Nacional de la Historia, pp. 61-69.

AGI, Santo Domingo, 641: 11-12-1656: Consulta dad a S.M. por el Consejo de Indias (Madrid, 11 diciembre de 1656) sobre la vuelta de los misioneros capuchinos a la conversión de los indios Cumanagotos. Madrid, 11 de diciembre de 1656. En Gómez Canedo, Lino (1967): Las misiones de Píritu. Documentos para su historia. Tomo I. Caracas, Academia Nacional de la Historia, p.p. 71-88.

AGI, Santo Domingo, 642: 11-01-1713. Informe del Obispo de Puerto Rico, comunicando al Rey la erección de doctrinas en la misión de Cumaná, las necesidades de la misma y los remedios que él juzga oportuno aplicar. Pueblo de Mariguitar, 11 de enero de 1713. En Carrocera, Buenaventura (1968): Misión de los Capuchinos en Cumaná. Tomo II. Caracas, Academia Nacional de la Historia, p.p. 349-352.

AGI, Santo Domingo, 644: 31-05-1752. Acuerdo de los religiosos capuchinos de la misión de Cumaná, Fray Antonio de Catalayud, Fray Antonio de Belchite y Fray Miguel de Vivel, sobre la restitución a los mismos de los pueblos por ellos fundados en la mencionada provincia y que estaban al cuidado de los sacerdotes seculares. Santa María de los Ángeles, 31 de mayo de 1752. En Carrocera, Buenaventura (1968): Misión de los Capuchinos en Cumaná. Tomo III. Caracas, Academia Nacional de la Historia, p.p. 173-194.

AGI, Santo Domingo, 705: 03-06-1735. Documentos en que, después de alegar la cédula (20 de enero 1657) y cabildo de la ciudad de Cumaná (3 de febrero de 1658) por el que se señaló territorio misional en aquella provincia a los Capuchinos, se prueba el derecho que a éstos les asistía de evangelizar los indios de la nación Paria, Martín Pellón y Palacio, Cumaná, 03 de junio de 1735. En Carrocera, Buenaventura (1968): Misión de los Capuchinos en Cumaná. Tomo III. Caracas, Academia Nacional de la Historia, p.p. 13-23. 


\section{REFERENCIAS BIBLIOGRÁFICAS}

Aguado, P. ([1581] 1950). Historia de Venezuela. Tomo I. Madrid: Maestre.

Amodio, E. (1991). Relaciones interétnicas en el Caribe indígena: Una reconstrucción a partir de los primeros testimonios europeos. Revista de Indias, 51(193), pp. 571-606.

Amodio, E (1998). Los caníbales mutantes. Etapas de transformación étnica de los Caribes durante la época colonial. Boletín Americanista, 9, pp. 8-29.

Arvelo Jiménez, N., F. Morales y H. Biord. (1989). Repensando la historia del Orinoco. Revista de Antropología, 5, pp. 155-174.

Augé, M. (1996). Hacia una Antropología de los mundos contemporáneos. Barcelona: Gedisa.

Balandier, G. (1993). La aprehensión del otro: Antropología desde fuera y Antropología desde dentro. Revista de Occidente, 140, pp. 35-42.

Boomert, A (2000). Trinidad, Tobago, and the Lower Orinoco interaction sphere: an archaeological/ethnohistorical study. Leiden: Universidad de Leiden.

Burguera, M. (1985). Instituciones de comunidad: Provincia de Cumaná, 1700-1828 (Vol. 36). Caracas: Academia Nacional de la Historia.

Butt-Colson, A. (1973). Inter-tribal trade in the Guiana Highlands. Antropológica, 34, pp. 5-70.

Butt-Colson, A. (1983-1984). The spatial component in the political structure of the Carib speakers of the Guiana Highlands: Kapon and Pemon. Antropológica, 5962, pp. 73-124.

Carrocera, B. (1968). Misión de los capuchinos en Cumaná. III tomos. Caracas: Academia Nacional de la Historia.

Casanova, J. (1991). La Historia Social y los historiadores. Barcelona: Crítica.

Caulín, Antonio ([1779] 1966). Historia de la Nueva Andalucía. Tomos I y II. Caracas: Academia Nacional de la Historia. 
Chukwudi Eze, E. (2001). El color de la razón: la idea de 'raza' en la Antropología de Kant. En W. Mignolo, Walter (comp.), Capitalismo y geopolítica del conocimiento: el eurocentrismo y la filosofía de la liberación en el debate intelectual contemporáneo (pp. 201-253). Buenos Aires: Ediciones del Signo.

Civrieux, M. (1980). Los Cumanagoto y sus vecinos. En A. Butt Colson (Editora), Los Aborígenes de Venezuela. Etnología Antigua. Tomo I. (pp. 27-240) Caracas: Fundación La Salle de Ciencias Naturales. Instituto Caribe de Sociología y Antropología.

Clifford, James ([1983] 1991) Sobre la autoridad etnográfica. En C. Reynoso (comp.), El surgimiento de la Antropología posmoderna (pp. 141-170). México D.F.: Gedisa.

Comaroff, J. y J. Comaroff (1992). Ethnography and the Historical Imagination. Boulder: Westview Press.

Coppens, Walter (1971). Las relaciones comerciales de los Yekuana del CauraParagua . Antropológica, 30, pp. 28-59.

Coronil, F. (2002). El Estado mágico. Naturaleza, dinero y modernidad en Venezuela. Caracas: Nueva Sociedad, Consejo de Desarrollo Científico y Humanístico, Universidad Central de Venezuela.

Dreyfus, S. (1983-1984). Historical and political anthropological inter-connections: the multilinguistic indigenous polity of the "Carib» Islands and Mainland Coast from the $16^{\text {th }}$ to the $18^{\text {th }}$ century. Antropológica, 59-62, pp. 39-56.

Duin, R. (2009). Wayana Socio-Political Landscapes: Multi-Scalar Regionality and Temporality in Guiana. PhD dissertation. Gainesville: University of Florida. .

Dussel, E. (2000). Europa, modernidad y eurocentrismo. En E. Lander (Ed.), La colonialidad del saber: eurocentrismo y Ciencias Sociales. Perspectivas latinoamericanas (p.p. 41-52). Caracas: UNESCO/FACES-UCV.

Fabian, J. (1983). Time and the Other. How Anthropology makes its object. Nueva York: Columbia University Press.

Foucault, M. ([1969] 1979). La Arqueología del saber. México D.F.: Siglo XXI. 
Gaboriau, M. (1969). Antropología estructural e Historia. En VV. AA., Estructuralismo e Historia (pp. 51-110). Buenos Aires: Nueva Visión.

Garzón Valdés, E. (1997). El problema ético de las minorías étnicas. En L. Olivé (comp.), Ética y diversidad cultural (pp. 31-57). México D.F.: Fondo de Cultura Económica.

Gassón, R. (1996). La evolución del intercambio a larga distancia en el Nororiente de Suramérica: Bienes de intercambio y poder político en una perspectiva diacrónica. En C. Langebaek y F. Cardenas-Arroyo (eds.), Caciques, intercambio y poder: interacción regional en el área intermedia de las Américas (pp. 133154). Bogotá: Universidad de los Andes.

Gassón, R. (2000). Quiripas and mostacillas: the evolution of shell beads as a medium of exchange in Northern South America. Ethnohistory, 47(3-4), pp. 581-610.

Gassón, R. (2002). Orinoquia: The Archaeology of the Orinoco River Basin. Journal of World Prehistory, 16(3), pp. 237-311.

Gassón, R. (2003). Ceremonial feasting in the Colombian and Venezuelan Llanos. Some remarks on its sociopolitical and historical significance. En N. Whitehead (ed.): Histories and Historicities in Amazonia (pp. 179-202). Lincoln/London: University of Nebraska Press.

Geertz, C. (1992). Historia y Antropología. Revista de Occidente, 137, pp. 55-74.

Geertz, C. ([1973] 1996). La interpretación de las culturas. Séptima edición en español. Barcelona: Gedisa.

Ginzburg, C. (1983). Señales. Raíces de un paradigma indiciario. En A. Gargani (ed.), La crisis de la razón (pp. 55-99). México D.F.: Siglo XXI.

Gómez Canedo, L. (1967). Las misiones de Píritu. Documentos para su Historia. Tomo I y II. Caracas: Academia Nacional de la Historia.

González Oropeza, H. (1985). Historia del estado Monagas. Maturín: Biblioteca de temas y autores monagenses.

Kuper, Adam ([1999] 2001). Cultura. La versión de los antropólogos. Barcelona: Paidós. 
Le Goff, J. (1991). El orden de la memoria. El tiempo como imaginario. Barcelona: Paidós.

Lévi-Strauss, C. ([1958] 1969). Antropología Estructural. Buenos Aires: Editorial Universitaria.

Lyotard, J. F. (1987). La condición posmoderna. Madrid: Ediciones Cátedra.

Lucena Giraldo, M. (1991). Laboratorio tropical. La Expedición de Límites al Orinoco, 1750-1767. Caracas: Monte Ávila Editores/Consejo Superior de Investigaciones Científicas.

Malinowski, B. ([1922] 1973). Los Argonautas del Pacífico Occidental. Barcelona: Planeta-Agostini.

Mansutti, A. (1986). Hierro, barro cocido, curare y cerbatanas. El comercio intra e interétnico entre los Uwotjuja. Antropológica, 65, pp. 3-75.

Marcus, G. y M. Fisher (1986). Anthropology as cultural critique. An experimental moment in the human sciences. Chicago: The University of Chicago Press.

Morales Méndez, F. (1990). Los hombres del onoto y la macana. Caracas: Fondo Editorial Tropykos.

Morey, R. y N. Morey (1975). Relaciones comerciales en el pasado en los llanos de Colombia y Venezuela. Montalbán, 4, pp. 533-565.

Nederveen Pieterse, J. (1996). Varieties of ethnic politics and ethnicity discourse. En E. N. Wilmsen y P. McAllister (eds.), The politics of difference: ethnic promises in a world of power. Chicago: The University of Chicago Press.

Ojer, P. (1966). La formación del Oriente venezolano. Caracas: Universidad Católica Andrés Bello.

Pagden, A. ([1982] 1988). La caída del hombre. El indio americano y los orígenes de la etnología comparativa. Madrid: Alianza Editorial.

Pandian, J. (1985). Anthropology and the Western Tradition Toward an Authentic Anthropology. Long Grove: Waveland Press. 
Pelleprat, P. ([1655] 1965). Relatos de las misiones de los padres de la Compañía de Jesús en las islas y Tierra Firme de la América meridional. Caracas: Academia Nacional de la Historia.

Prato-Perelli, A. (1990). Las Encomiendas de Nueva Andalucía en el siglo XVII. IV tomos. Caracas: Academia Nacional de la Historia.

Rival, L. (2002). Trekking Through History: The Huaorani of Amazonian Ecuador. Nueva York: Columbia University Press.

Rosaldo, R. ([1989] 2000). Cultura y verdad. La reconstrucción del análisis social. Quito: Ediciones Abya-Yala.

Sahlins, M. ([1985] 1997). Islas de Historia: La muerte del capitán Cook. Metáfora, Antropología e Historia. Tercera edición en español. Barcelona: Gedisa.

Sapir, E. ([1921] 1975). El lenguaje. Introducción al estudio del habla. México D.F.: Fondo de Cultura Económica.

Taussig, M. (2002). Chamanismo, colonialismo y el hombre salvaje: un estudio sobre el terror y la cultura.(Trad) Hernando Valencia Goelkel. Bogotá: Editorial Norma.

Taylor, C. (1989). Sources of the self: The making of the modern identity. Cambridge: Harvard University Press.

Thomas, D. (1972). The indigenous trade system of Southeast Estado Bolívar, Venezuela. Antropológica, 33, pp. 3-37.

Tiapa, F. (2008). Resistencia indígena e identidades fronterizas en la colonización del Oriente de Venezuela, siglos XVI-XVIII. Antropológica, 109, pp. 69-112.

Tiapa, Francisco (2013). Formulación de un modelo teórico para el análisis de la estructura y transformación histórica del Sistema interétnico del Golfo de Paria durante la época colonial. Caracas: Instituto Venezolano de Investigaciones Científicas.

Wallerstein, I. (1976). The modern World System I. Capitalist agriculture and the origins of the European World-Economy in the Sixteenth Century Nueva York: Academic Press. 
Wallerstein, I. ([1996] 2006). Abrir las Ciencias Sociales. Informe de la Comisión Gulbenkian para la reestructuración de las Ciencias Sociales. Madrid: Siglo XXI.

Whitehead, N. (1988). Lords of the tiger spirit. A History of the Caribs in Colonial Venezuela and Guyana. 1498-1820. Dordhrecht/Leiden: Royal Institute of Linguistics and Anthropology, Caribbean Studies Series.

Whorf, B. L. ([1956] 1971). Lenguaje, pensamiento y realidad. Barcelona: Barral editores.

Zent, S. (2009). The political ecology of ethnic frontiers and relations among the Piaroa of the middle Orinoco. En M. Alexaides (ed.) Mobility and Migration in Indigenous Amazonia (pp-167-194). Londres: Berghahm Books:.

Zucchi, A. y R. Gassón (2002). Elementos para una interpretación alternativa de los circuitos de intercambio indígena en los llanos de Venezuela y Colombia durante los siglos XVI y XVIII. Arqueología del Área Intermedia, 4, pp. 65-87. 